\title{
Endobronchial Ultrasound for the Diagnosis of Centrally Located Lung Tumors: A Systematic Review and Meta-Analysis
}

\author{
Jolanda C. Kuijvenhoven ${ }^{a, b}$ Fausto Leoncini ${ }^{a, c} \quad$ Laurence C. Crombag ${ }^{a}$ \\ René Spijker $^{d}$ Peter I. Bonta ${ }^{a}$ Daniël A. Korevaare Jouke T. Annema ${ }^{\mathrm{a}}$ \\ a Department of Respiratory Medicine, Academic Medical Center, University of Amsterdam, Amsterdam, The \\ Netherlands; ${ }^{b}$ Department of Respiratory Medicine, Medisch Centrum Leeuwarden, Leeuwarden, The Netherlands; \\ 'Section of Respiratory Medicine, Careggi University Hospital, Florence, Italy; ${ }^{\mathrm{d}}$ Medical Library, Academic Medical \\ Center, University of Amsterdam, Amsterdam, The Netherlands; ${ }^{e}$ Department of Clinical Epidemiology, Biostatistics \\ and Bioinformatics, Academic Medical Center, University of Amsterdam, Amsterdam, The Netherlands
}

\section{Keywords}

Lung cancer · Diagnosis · Endobronchial ultrasound · Tumor

\begin{abstract}
Introduction: Obtaining a tissue diagnosis of centrally located lung tumors in patients presenting without endobronchial abnormalities is challenging, and therefore a considerable diagnostic problem. Objective: The objective of this study was to evaluate the performance of linear endobronchial ultrasound guided-transbronchial-needle aspiration (EBUS-TBNA) for the diagnosis of centrally located lung tumors. Methods: We performed a systematic review (PROSPERO, CRD42017080968) and searched MEDLINE, Embase, BIOSIS Previews, and Web of Science till November 18, 2018 for studies that evaluated the yield and/or sensitivity of EBUS-TBNA for diagnosing centrally located lung tumors. We assessed the study quality using QUADAS-2 and performed random-effects meta-analysis. Results: A total of 5,657 manuscripts were identified; of these 14 were considered for the study, including 1,175 patients who underwent EBUS-TBNA for diagnosing an intrapulmonary tumor. All studies had a high risk of bias or applicability concerns, predominately regarding patient selection. The average yield of
\end{abstract}

\begin{tabular}{ll}
\hline karger@karger.com & (c) 2019 The Author(s) \\
www.karger.com/res & Published by S. Karger AG, Basel \\
& This article is licensed under the Creative Commons Attribution- \\
Narger & NonCommercial-NoDerivatives 4.0 International License (CC BY- \\
NC-ND) (http://www.karger.com/Services/OpenAccessLicense). \\
Usage and distribution for commercial purposes as well as any dis- \\
tribution of modified material requires written permission.
\end{tabular}

EBUS-TBNA for diagnosing centrally located lung tumors was 0.89 (95\% Cl 0.84-0.92) and average sensitivity for diagnosing malignant tumors was 0.91 (95\% Cl 0.88-0.94). Among studies reporting this information, EBUS-related complications occurred in $5.4 \%$ of patients (42/721). Conclusion: EBUS-TBNA has a high yield and sensitivity for diagnosing centrally located lung tumors and is safe in selected patients. Prospective studies are recommended to evaluate the routine use of this procedure for diagnosing intrapulmonary tumors.

(c) 2019 The Author(s)

Published by S. Karger AG, Basel

\section{Introduction}

Lung cancer is the leading cause of cancer-related mortality in the world [1]. If lung cancer is suspected, a tissue diagnosis should be obtained to establish a definite diagnosis. In patients with centrally located lung tumors suspected for lung cancer, current clinical guidelines recommend conventional flexible bronchoscopy with biop-

J.C.K. and F.L. contributed equally to this work.
Jouke T. Annema, MD, PhD

Department of Respiratory Medicine, Academic Medical Center University of Amsterdam, Meibergdreef 9

NL-1105 AZ Amsterdam (The Netherlands)

E-Mail j.t.annema@amc.uva.nl 
sy or transbronchial-needle aspiration (TBNA) to obtain a diagnosis [2]. However, bronchoscopy is non-diagnostic in a considerable proportion of patients, especially in the absence of endobronchial abnormalities [3]. Computed tomography (CT) guided transthoracic needle aspiration can be used to obtain a diagnosis, but for centrally located lung tumors this technique has a high risk of complications including pneumothorax and bleedings [3]. Moreover, such tumors are frequently inaccessible for a transthoracic approach, and the diagnostic yield is lower than for peripheral lung tumors $[4,5]$.

Current staging guidelines advocate endobronchial and esophageal ultrasound (EBUS and EUS-[B]) as the techniques of choice for mediastinal nodal tissue staging of non-small cell lung cancer [6-8]. In patients in whom CT imaging shows a centrally located lung tumor adjacent to the major airways, endobronchial endoscopic ultrasound-guided fine-needle aspiration (EBUS-TBNA) is suggested for diagnostic purposes following a non-diagnostic conventional bronchoscopy $[6,9]$.

Although the EBUS technique for mediastinal nodal staging of lung cancer has rapidly spread, its role in obtaining an adequate tissue sample directly from intrapulmonary tumors has received much less attention. If sufficiently feasible and accurate, diagnosing lung tumors through EBUS could have major logistic advantages, as tumor and mediastinal nodal staging can be performed in the same session $[6,10]$.

Various reports regarding the role of EBUS-TBNA in the diagnosis of centrally located lung tumors have been published, but its feasibility, yield, sensitivity, and safety are not well-established [6]. Therefore, we conducted a systematic review and meta-analysis with the aim of obtaining summary estimates of the yield and sensitivity of EBUS-TBNA for diagnosing centrally located lung tumors in patients with suspected lung cancer.

\section{Material and Methods}

The protocol of this systematic review was prospectively registered at PROSPERO under registration number CRD42017080968. This review is reported following the PRISMA-DTA guidelines [11].

\section{Eligibility Criteria}

Studies were included if they evaluated the yield and/or sensitivity of EBUS-TBNA for diagnosing centrally located lung tumors adjacent or near the major airways - with the aim of obtaining a tissue sample from the suspected lesion. Various definitions of a centrally located lung tumor exist and we followed those as reported by the authors of the primary studies. Studies were eligible for analysis regardless of whether patients were selected based on the results of previous tests. If studies aimed to obtain a tissue diagnosis from centrally located lung tumors invading the mediastinum or central vessels, they were also included. However, we excluded studies that focused on diagnosing mediastinal tumors, studies that aimed to diagnose lung cancer by sampling mediastinal nodes, liver lesions or left adrenal gland lesions, and studies focusing on lung cancer staging rather than diagnosis. We also excluded studies using a radial instead of a linear EBUS scope, and studies including $<10$ patients with centrally located lung tumors.

\section{Literature Search Strategy and Selection}

We searched for eligible studies in MEDLINE (Ovid), Embase (Ovid), BIOSIS Previews (Ovid), and Web of Science. Searches were developed by a medical information specialist (R.S.). No date or language restrictions were applied. The complete search strategy is provided in online supplementary Appendix (online suppl. Table S1; for all online suppl. material, see www.karger.com/ doi/10.1159/000500363). The final search was performed on November 18, 2018. We checked reference lists of all included papers for additional studies.

Two authors (J.C.K. and L.C.C.) independently reviewed the titles and abstracts of all search results for eligibility. If an article was considered potentially eligible, both authors independently examined the full article for inclusion. Disagreements were resolved after discussion with a third author (J.T.A.).

\section{Data Extraction and Synthesis}

Data were extracted from included studies by 2 authors (J.C.K. and F.L.). We extracted the first author, year of publication, journal of publication, and country of patient recruitment. We also extracted whether or not patients had received previous tests to obtain a biopsy-based diagnosis of the centrally located tumor. We extracted details about age and gender, availability of rapid on-site cytological evaluation (ROSE), needle type, number of needle passes performed, procedure length, tumor size, the number of patients with endobronchial abnormalities, the reference standard, and any complications induced by EBUS-TBNA.

Furthermore, we extracted the total number of patients in whom EBUS-TBNA was performed with the aim of diagnosing a centrally located lung tumor, the number of patients in whom an adequate tissue sample was obtained by EBUS-TBNA, the number of patients in whom EBUS-TBNA made a correct biopsy-proven diagnosis (malignant or non-malignant), the number of patients in whom EBUS-TBNA diagnosed a malignancy, and the number of patients in whom the targeted intrapulmonary tumor turned out to be malignant, according to the reference standard.

EBUS-TBNA was considered to have reached an inadequate diagnosis if additional diagnostics were needed to obtain a correct diagnosis (e.g., because the tumor could not be visualized or sampled through EBUS-TBNA), or if the reference standard reached a different diagnosis. EBUS-TBNA was considered to have reached a correct diagnosis if the reference standard resulted in the same diagnosis, or if EBUS-TBNA tissue samples contained malignant cells as in such cases a reference standard is rarely performed.

Risk of Bias and Applicability Concerns Assessment

Two authors (J.C.K. and F.L.) independently assessed study quality using the QUADAS-2 tool [12]. Disagreements were resolved by consensus and in difficult cases, 2 other authors (L.C.C. 
Fig. 1. Flowchart of the selection process of the included studies. EBUS, endobronchial ultrasound.

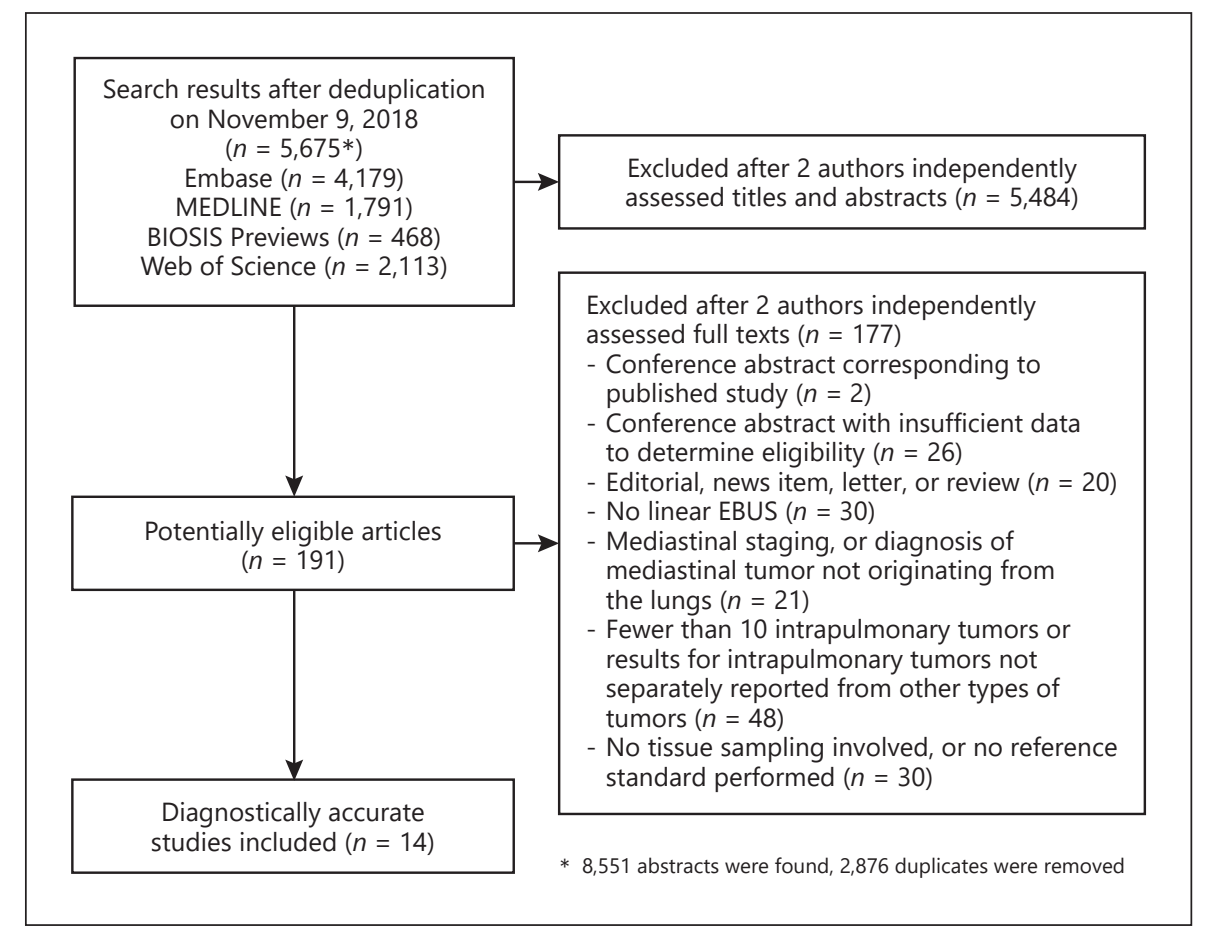

and D.A.K.) made the final decision. Study designs with a high risk of bias or applicability concerns included: (1) retrospective (nonconsecutive) inclusion of patients; (2) exclusion of patients in whom the intrapulmonary tumor could not be visualized by EBUS; (3) a case-control design; (4) exclusion of patients that did not match the review question; (5) endoscopists that were not blinded to the final diagnosis while performing EBUS; (6) a suboptimal reference standard for patients with a non-diagnostic or non-malignant EBUS-TBNA (e.g., clinical follow-up instead of surgical-pathological verification); (7) partial or (8) differential verification of patients with a non-diagnostic or non-malignant EBUS-TBNA; (9) exclusion of patients with missing reference standard results.

\section{Primary Outcomes}

The primary outcomes of this review were: (1) the yield of EBUS-TBNA for diagnosing centrally located lung tumors and (2) the sensitivity of EBUS-TBNA for diagnosing malignant centrally located lung tumors.

Yield was defined as the number of patients in whom EBUSTBNA made a correct tissue diagnosis, relative to the total number of patients in whom EBUS was performed with the aim of diagnosing a centrally located lung tumor.

Sensitivity was defined as the number of patients in whom EBUS-TBNA made a correct tissue diagnosis of any malignancy, relative to the total number of patients in whom the targeted centrally located lung tumor turned out to be malignant.

\section{Analysis}

We calculated estimates of yield and sensitivity of the included studies with 95\% CIs, using the normal approximation. We then performed a univariate random effects meta-analysis according to DerSimonian-Laird [13]. Data analyses were performed in the "meta" package in R version 3.0.

\section{Results}

\section{Study Selection and Study Characteristics}

The searches identified 5,675 results. After screening titles and abstracts, 191 potentially eligible articles remained, of which 14 studies were included in the final analysis [9, 14-26]. Of these, 3 were conference abstracts. Figure 1 provides the details of the study selection and the reasons for excluding studies.

Across included studies various definitions for the targeted lung tumors were used, ranging from "central lung parenchymal lesions" [16] to "an intrapulmonary mass with the medial margin located within the inner third of the hemi-thorax based on chest CT-scan imaging" [14]. Table 1 summarizes the different definitions used for centrally located lung tumors across the included studies.

Table 2 shows detailed characteristics of the 14 included studies. The first article was published in 2008 and the last in 2018. Nine studies reported the proportion of patients that underwent a previous non-diagnos- 
Table 1. Definitions of targeted intrapulmonary lesions

\begin{tabular}{|c|c|}
\hline Study [ref.], year & Targeted intrapulmonary tumors were defined as \\
\hline $\begin{array}{l}\text { Nakajima et al. [9], } \\
2008\end{array}$ & $\begin{array}{l}\text { Pulmonary masses whose drainage bronchus is difficult to be reached such as } \\
\text { mediastinal type lung cancer adjacent to the trachea, lesions adjacent to the main } \\
\text { bronchus or the segmental bronchus }\end{array}$ \\
\hline $\begin{array}{l}\text { Tournoy et al. [14], } \\
2009\end{array}$ & $\begin{array}{l}\text { The centrally located lung lesions were defined as an intrapulmonary mass with } \\
\text { the medial margin located within the inner third of the hemi-thorax based on chest } \\
\text { CT-scan imaging }\end{array}$ \\
\hline $\begin{array}{l}\text { Khan et al. [16], } \\
2012\end{array}$ & Central lung parenchymal lesions \\
\hline $\begin{array}{l}\text { Bhatti et al. [17], } \\
2013\end{array}$ & Centrally located peribronchial lung lesions \\
\hline $\begin{array}{l}\text { Verma et al. [18], } \\
2013\end{array}$ & $\begin{array}{l}\text { Centrally located lung lesions were defined as an intrapulmonary nodule or mass lo- } \\
\text { cated adjacent to the tracheobronchial tree as visualized on chest CT scan }\end{array}$ \\
\hline $\begin{array}{l}\text { Yang et al. [19], } \\
2013\end{array}$ & Parabrachial or parabronchial intrapulmonary lesions proved by CT scan \\
\hline $\begin{array}{l}\text { Zhao et al. [20], } \\
2013\end{array}$ & Intrapulmonary lesions located near the central airway \\
\hline $\begin{array}{l}\text { Evison et al. [21], } \\
2013\end{array}$ & Intra-parenchymal lung lesions \\
\hline $\begin{array}{l}\text { Argento et al. [22], } \\
2016\end{array}$ & $\begin{array}{l}\text { Centrally located intraparenchymal lesions } \\
\text { Lesions completely surrounded by lung parenchyma were included }\end{array}$ \\
\hline $\begin{array}{l}\text { Chen et al. [23], } \\
2017\end{array}$ & Peribronchial lung lesions \\
\hline
\end{tabular}

tic conventional bronchoscopy, ranging from 33 to $100 \%$; information on previous bronchoscopy was not reported in the remaining 5 studies. The mean/median age of the patients ranged from 56 to 69 year, and the ratio of male patients ranged from 31 to $83 \%$. ROSE was available in 6 studies, not available in 4 studies, and 4 studies did not report on the availability of ROSE. The type of needle that was used was a 22 Gauge needle in 11 studies, both 21- or 22-Gauge needles in 1 study, and not reported in 2 studies. Six studies reported on the number of needle aspirates, which varied from 2 to 6 . Three studies reported on the mean/median procedure length: 21 , 46 , and $56 \mathrm{~min}$. The mean/median tumor size ranged from 25 to $53 \mathrm{~mm}$. Seven studies (542 patients in total) explicitly excluded patients with endobronchial abnormalities or did not encounter such patients, and 3 studies explicitly included patients with endobronchial abnormalities (27 patients with endobronchial abnormalities in total). The remaining 4 studies made no comments regarding the presence of patients with endobronchial abnormalities.

\section{Risk of Bias and Applicability Concerns}

Detailed results of the quality assessment of included studies are available in the online supplementary appendix (online suppl. Table S2). All studies had at least one item with a high risk of bias and/or applicability concerns. The most common source of bias was the retrospective inclusion of patients, which was the case in 12 of 14 included studies. It was unclear for 11 studies whether inappropriate exclusions were avoided, which we considered the case if patients in whom the tumor could not be visualized by EBUS were excluded. The quality of the reference standard, in the absence of a specific diagnosis following EBUS, was variable ranging from surgical-pathological verification to clinical follow-up.

\section{Diagnostic Yield and Sensitivity}

Table 3 shows the estimates of yield and sensitivity for the individual studies. The total number of patients included in this review is 1,175 ; the number of patients included in the individual studies ranged from 32 to 290. The proportion of patients with a final diagnosis of ma- 


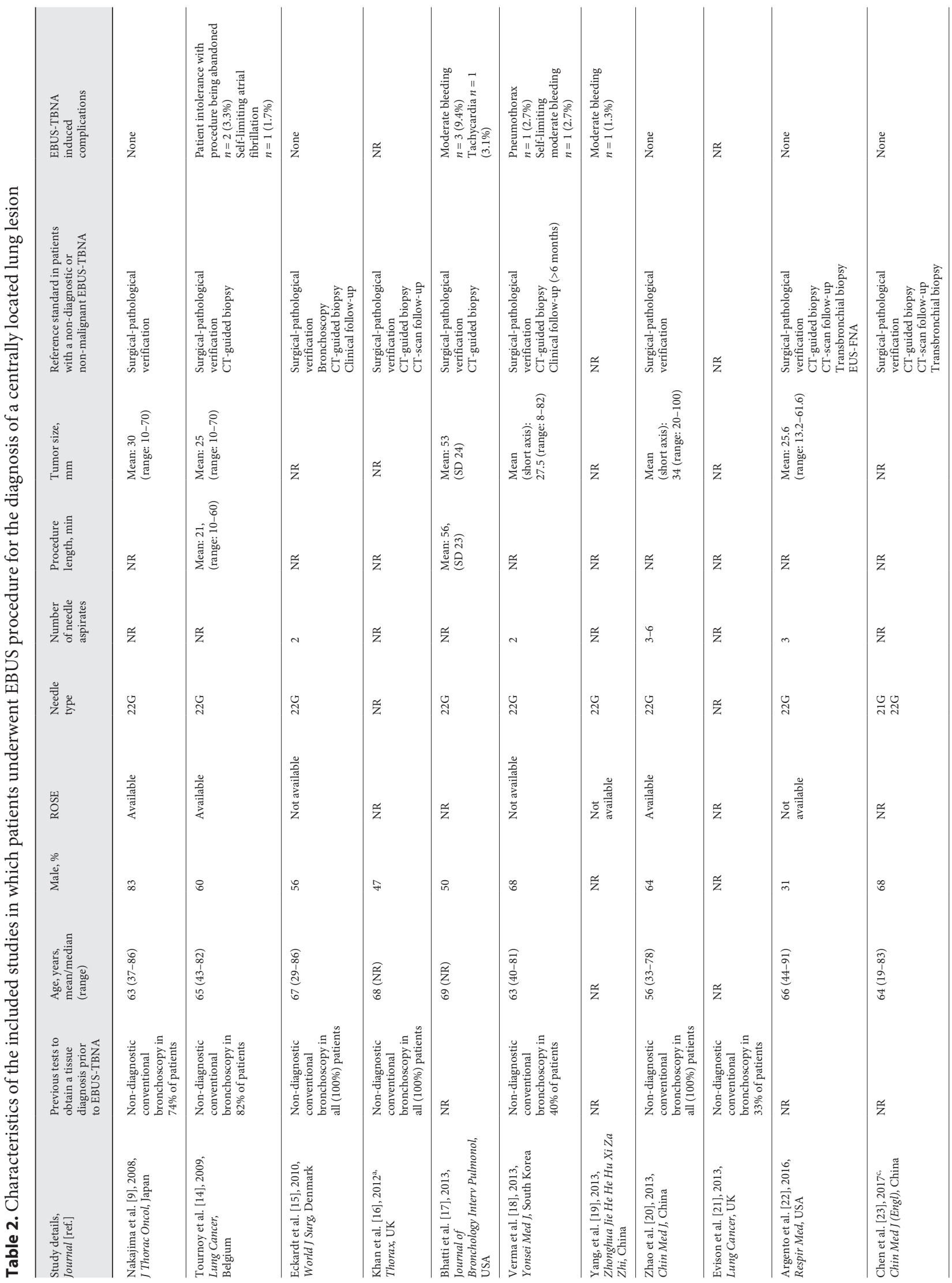




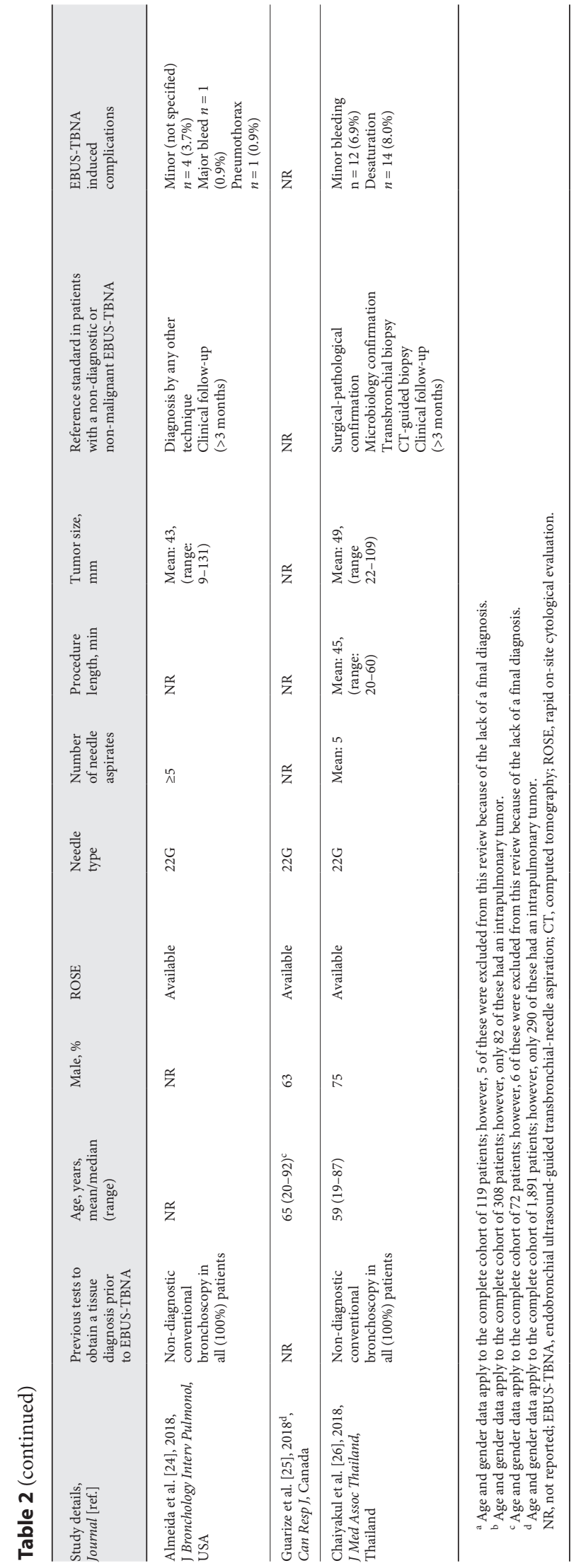

lignancy varied from 62 to $100 \%$. Final diagnosis of malignancy included non-small cell lung cancer in 620 patients, SCLC in 126 patients and another malignant diagnosis in 61 among 12 studies reporting this information. Detailed information about the final diagnosis is available on the online supplementary appendix (online suppl. Table S3).

The yield of EBUS-TBNA for diagnosing intrapulmonary lesions ranged from 0.72 to 0.96 across the included studies; 1 study did not report sufficient information to calculate yield. The average yield after meta-analysis was 0.89 (95\% CI 0.84-0.92; Fig. 2). The sensitivity of EBUSTBNA for diagnosing malignant intrapulmonary tumors ranged from 0.77 to 0.97 across included studies; 1 study did not report sufficient data to calculate sensitivity. The average sensitivity after meta-analysis was 0.91 (95\% CI 0.88-0.94; Fig. 3).

\section{Complications}

In 5 studies (281 patients) there were no complications due to EBUS-TBNA, and in 3 studies (453 patients) this information was not reported. In the remaining 6 studies (490 patients), a total of 42 complications were reported: major bleed $(n=1)$, moderate/self-limiting bleeding $(n=$ $17)$, atrial fibrillation $(n=1)$, tachycardia $(n=1)$, intolerance with the procedure $(n=2)$, pneumothorax $(n=2)$, desaturation $(n=14)$, and a minor complication that was not specified $(n=4)$. Overall, among studies reporting this information, the complication rate was 5.4\% (42/721), although many of these can be considered as minor.

\section{Discussion}

In this systematic review, we found that EBUS-TBNA has a high yield and sensitivity for diagnosing centrally located lung tumors. The findings of this study are clinically relevant as tissue acquisition of centrally located lung tumors without endobronchial abnormalities is a large clinical problem. The current analysis seems to imply that under the condition that the tumor is located adjacent to the major airways, a diagnosis can be obtained through EBUS-TBNA in approximately 9 out of 10 patients with low risk of complications.

Some limitations should be discussed regarding the studies under consideration. All studies included in this systematic review had a high risk of bias or applicability concerns when assessed by QUADAS-2 [12]. Especially the fact that almost no prospective studies on the topic have been performed is surprising. Because of this, yield 
Table 3. Yield and sensitivity for EBUS-TBNA for the diagnosis of centrally located intrapulmonary lesions

\begin{tabular}{|c|c|c|c|c|c|c|c|}
\hline Study [Ref.], years & $\begin{array}{l}\text { Total EBUS } \\
\text { performed, } n\end{array}$ & $\begin{array}{l}\text { Total with any } \\
\text { malignancy, } n(\%)\end{array}$ & $\begin{array}{l}\text { Adequate } \\
\text { tissue sample by } \\
\text { EBUS-TBNA, } n(\%)\end{array}$ & $\begin{array}{l}\text { Correct } \\
\text { diagnosis by } \\
\text { EBUS-TBNA, } n\end{array}$ & $\begin{array}{l}\text { Correct diagnosis } \\
\text { of any malignancy by } \\
\text { EBUS-TBNA, } n\end{array}$ & $\begin{array}{l}\text { Yield for correct } \\
\text { diagnosis }^{\mathrm{a}},(95 \% \mathrm{CI})\end{array}$ & $\begin{array}{l}\text { Sensitivity for } \\
\text { malignancy } \\
(95 \% \mathrm{CI})\end{array}$ \\
\hline Nakajima et al. [9], 2008 & 35 & $34(97)$ & $35(100)$ & 33 & 32 & $0.94(0.80-0.99)$ & $0.94(0.79-0.99)$ \\
\hline Tournoy et al. [14], 2009 & 60 & $58(97)$ & $46(77)$ & 46 & 46 & $0.77(0.64-0.86)$ & $0.79(0.67-0.88)$ \\
\hline Eckardt et al. [15], 2010 & 82 & $51(62 \%)$ & $79(96)$ & 59 & 48 & $0.72(0.61-0.81)$ & $0.94(0.83-0.98)$ \\
\hline Khan et al. [16], 2012 & 114 & $111(95)$ & $113(99)$ & 110 & 108 & $0.96(0.91-0.99)$ & $0.97(0.92-0.99)$ \\
\hline Bhatti et al. [17], 2013 & 32 & $32(100)$ & NR & 30 & 30 & $0.94(0.78-0.98)$ & $0.94(0.78-0.98)$ \\
\hline Verma et al. [18], 2013 & 37 & $33(89)$ & NR & 32 & 32 & $0.86(0.71-0.94)$ & $0.97(0.81-1.00)$ \\
\hline Yang et al. [19], 2013 & 78 & $65(83)$ & NR & 75 & 62 & $0.96(0.89-0.99)$ & $0.95(0.87-0.99)$ \\
\hline Zhao et al. [20], 2013 & 66 & $63(95)$ & $66(100)$ & 59 & 59 & $0.89(0.79-0.95)$ & $0.94(0.84-0.98)$ \\
\hline Evison et al. [21], 2013 & 49 & $47(95)$ & NR & NR & 38 & - & $0.81(0.67-0.90)$ \\
\hline Argento et al. [22], 2016 & 32 & $30(94)$ & NR & 27 & 26 & $0.84(0.68-0.93)$ & $0.87(0.69-0.95)$ \\
\hline Chen et al. [23], 2017 & 66 & $56(85)$ & NR & 56 & 48 & $0.85(0.74-0.92)$ & $0.86(0.74-0.93)$ \\
\hline Almeida et al. [24], 2018 & 108 & $93(86 \%)$ & NR & 94 & 88 & $0.87(0.79-0.92)$ & $0.95(0.88-0.98)$ \\
\hline Guarize et al. [25], 2018 & 290 & NR & NR & 266 & 241 & $0.92(0.88-0.94)$ & - \\
\hline Chaiyakul et al. [26], 2018 & 175 & $147(84 \%)$ & NR & 158 & 135 & $0.90(0.85-0.94)$ & $0.92(0.86-0.95)$ \\
\hline
\end{tabular}

a Yield was calculated as the number of patients in whom EBUS-TBNA made a correct tissue diagnosis (non-malignant or malignant) divided by the total number of patients in whom EBUS was performed with the aim of diagnosing an intrapulmonary tumor.

${ }^{b}$ Sensitivity was calculated as the number of patients in whom EBUS-TBNA made a correct tissue diagnosis of malignancy divided by the total number of patients in whom the targeted intrapulmonary tumor turned out to be malignant.

NR, not reported; EBUS, endobronchial ultrasound; EBUS-TBNA, endobronchial ultrasound-guided transbronchial-needle aspiration.

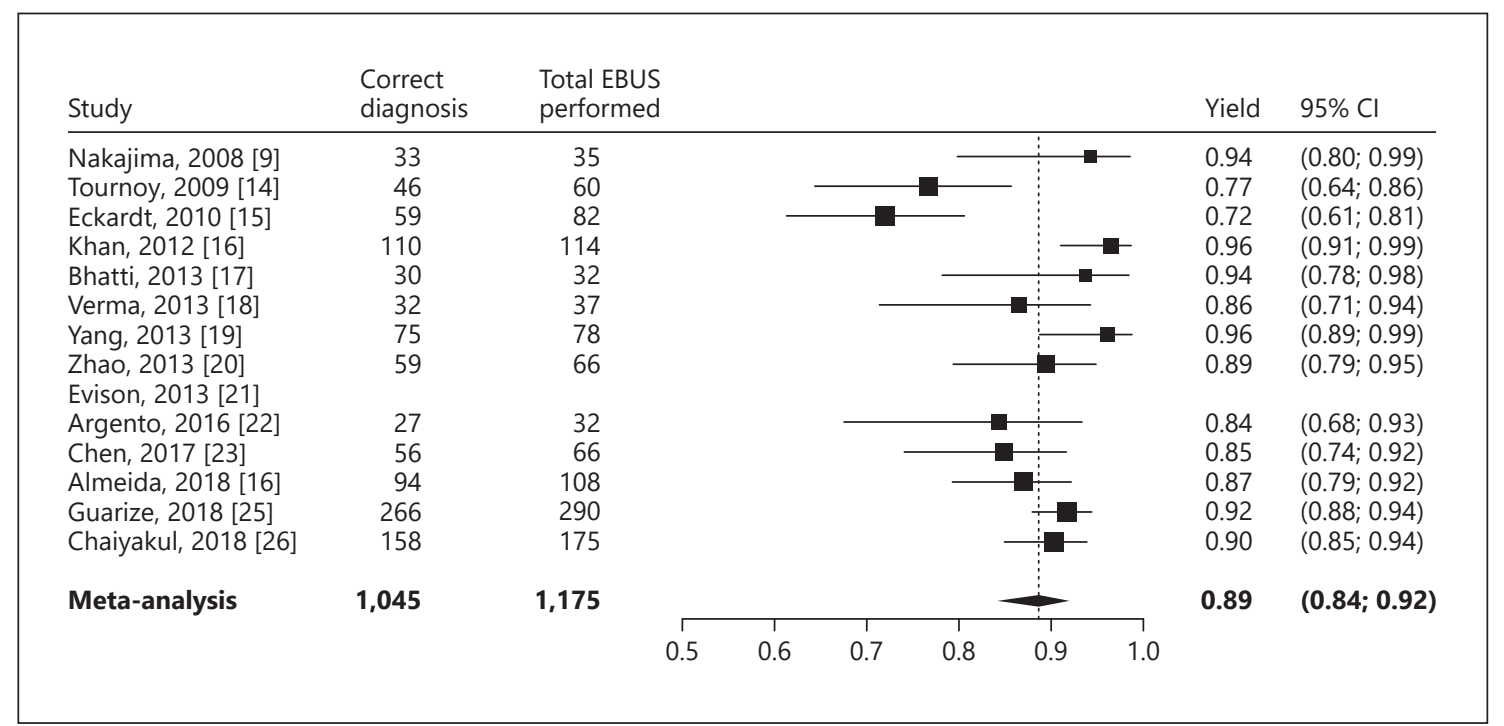

Fig. 2. Yield of EBUS-TBNA for diagnosing centrally located intrapulmonary lesions. EBUS, endobronchial ultrasound.

and sensitivity may have been overestimated. In addition, several different definitions of a centrally located lung tumor were used in the included studies, ranging from the inner one third (American College of Chest Physicians guidelines) [8] to the inner two thirds (European Society of Thoracic Surgery guidelines and National Comprehensive Cancer Network) [7, 27] of the hemi-thorax.

Variations operator's experience, lesion size, localization in relation to the major airways, and the availability of ROSE are key factors that may affect the performance of EBUS-TBNA [28]. Such heterogeneity could lead to major variation in yield and sensitivity across clinical settings, but the limited number of eligible studies and incomplete reporting in some of them, did not allow us to perform sensitivity analyses. However, average estimates of yield and sensitivity were relatively consistent across individual studies, suggesting that EBUS-TBNA may be useful in different clinical settings. 


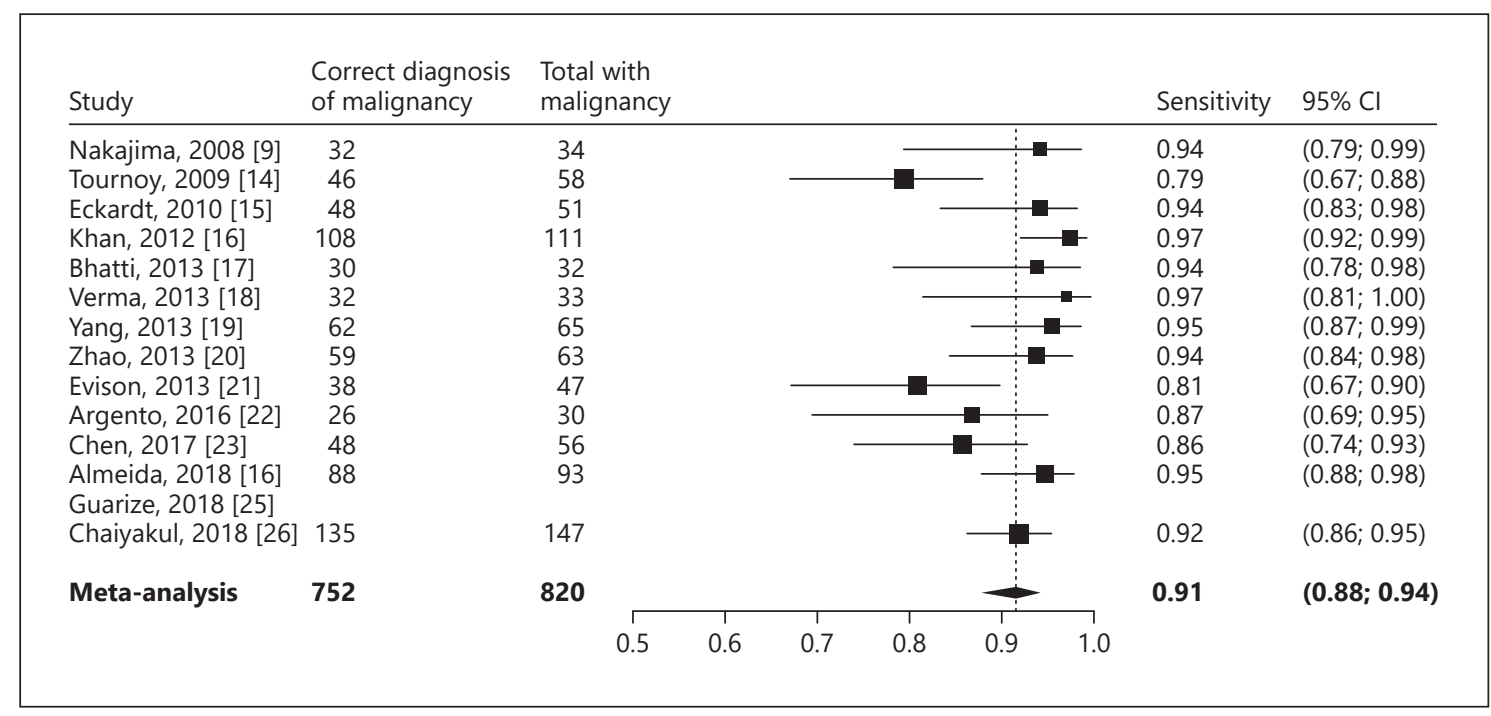

Fig. 3. Sensitivity of EBUS-TBNA for diagnosing malignant centrally located intrapulmonary tumors.

Seven studies explicitly excluded or did not encounter patients with endobronchial abnormalities and 3 studies explicitly reported to have included several patients with such abnormalities. Among these 10 studies, only 27 of 660 (4\%) patients showed endobronchial abnormalities. Therefore, it is unlikely that the presence of endobronchial lesions has overestimated the yield and sensitivity of EBUS-TBNA in diagnosing centrally located lung tumors in our review.

We found a high proportion of patients with malignancy across the included studies. This may, again, be related to the retrospective nature of most studies; some may have only selected patients with a high likelihood of malignancy. The prevalence of malignant tumors is likely to be lower in practice.

Complications occurred in only $5.8 \%$ of patients, with just 2 serious adverse events (a major bleed which needed an intervention and one pneumothorax). These numbers are comparable with those reported in previous studies on EBUS-TBNA related complications in sampling nodes and mediastinal masses [29]. The most common complication was self-limiting bleeding, and only 2 patients had a pneumothorax due to EBUS-TBNA, thus suggesting that a routine chest X-ray after EBUS-FNA of intrapulmonary tumors may not be indicated.

EBUS-TBNA is a cost-effective lung cancer staging procedure that can be performed in outpatients under moderate sedation [30]. Moreover, it provides the advantage that it can combine lung tumor diagnosis and loco regional mediastinal and hilar staging in a single procedure. Endosonography is very operator-dependent and should be learned and performed in a systematic way $[4,28]$. There is a need for learning and certification programs in endosonography such as the "ERS comprehensive training program" to train qualified doctors to be able to independently and competently perform EBUS [31]. Besides nodal assessment, diagnosing intrapulmonary tumors should be part of training programs.

A substantial number of studies have evaluated the performance of EBUS-TBNA in diagnosing mediastinal tumors and in mediastinal nodal staging in patients with lung cancer [32], and this application is now recommended in most clinical guidelines $[7,8]$. However, the number of evaluations on the performance of EBUS-TBNA in diagnosing intrapulmonary tumors is limited and almost all are retrospective [6]. Based on our own experience, for patients with a previous non-diagnostic bronchoscopy, we believe that EBUS-TBNA should be considered for those patients who present with an intrapulmonary tumor located adjacent or near the larger airways, especially in case of the absence of endobronchial lesions or nodal metastases. Future prospective studies with clear definitions of a centrally located lung tumor are advised to confirm the current findings. The definition of the tumor positioned within the inner one third of the hemi-thorax by drawing concentric lines from the midline may qualify best [33]. 
Despite the parenchymal origin of the lesion, linear EBUS seems more useful then radial EBUS for the analysis of centrally located lung tumors without endobronchial abnormalities. Radial EBUS can be used to detect lung lesions provided an airway reaches the lesion; however, a real-time controlled aspiration is not possible [3436].

Also conventional TBNA - without EBUS guidance can also be used for primary lung tumor analysis [2]. The needle can be placed on a widened carina or inserted on a specific location in the airways based on chest CT scan findings. The diagnostic yield of conventional TBNA depends on the size and the location of the lung tumor, and a diagnostic yield of 56\% was reported [2]. A comparison study between EBUS guided TBNA and conventional TBNA has not been performed.

A recent meta-analysis of our group reported a high yield and sensitivity of EUS-(B)-FNA for diagnosing centrally located intrapulmonary tumors in case the lung mass is located adjacent the esophagus [37]. Using EUS(B)-FNA, left sided and lower paraesophageal nodes and tumors can be reached [10]. As such, it is complementary to EBUS-TBNA, which provides access to structures close to the large airways on both sides [38]. A combined approach of EBUS-TBNA and EUS-B-FNA for mediastinal lymph node staging is increasingly performed in clinical practice $[3,8]$. Such an approach could also be useful in the diagnosis of centrally located intrapulmonary tumors
[39]. A combined EBUS and EUS procedure using just the EBUS scope for both nodal and tumor diagnosis is an elegant minimally invasive diagnostic approach.

In conclusion, the present systematic review and meta-analysis implies that EBUS-TBNA is a safe procedure with a high yield and sensitivity for diagnosing centrally located lung tumors. However, caution should be taken to extrapolate these results into routine real-life practice due to the lack of high-quality studies included. Future prospective studies are indicated to evaluate whether the current findings are reproducible and to further refine the criteria for recommending EBUS-TBNA in this setting.

\section{Disclosure Statement}

Dr. Jouke T. Annema received financial and material support for educational EBUS courses from Hitachi, Pentax and COOK; lecture fees from Pentax and a research grant from $\mathrm{COOK}$ medical. Dr. Peter I. Bonta reports grants and other support from Boston Scientific, other from COOK, other from Nuvaira, other from Pentax, non-financial support from Olympus, grants from St Jude Mecial. Other authors: none.

\section{Funding Source}

This research did not receive any specific grant from funding agencies in the public, commercial, or not-for-profit sectors.

\section{References}

1 Global Burden of Disease Cancer C, Fitzmaurice $\mathrm{C}$, Allen C, Barber RM, Barregard L, Bhutta ZA, Brenner H, et al. Global, Regional, and National Cancer Incidence, Mortality, Years of Life Lost, Years Lived With Disability, and Disability-Adjusted Life-years for 32 Cancer Groups, 1990 to 2015: A Systematic Analysis for the Global Burden of Disease Study. JAMA Oncol. 2017 Apr;3(4):524-48.

2 Rivera MP, Mehta AC, Wahidi MM. Establishing the diagnosis of lung cancer: Diagnosis and management of lung cancer, 3rd ed: American College of Chest Physicians evidence-based clinical practice guidelines. Chest. 2013 May;143(5 Suppl):e142S-65S.

3 Boskovic T, Stanic J, Pena-Karan S, Zarogoulidis P, Drevelegas K, Katsikogiannis N, et al. Pneumothorax after transthoracic needle biopsy of lung lesions under CT guidance. J Thorac Dis. 2014 Mar;6 Suppl 1:S99-107.

4 Arslan S, Yilmaz A, Bayramgürler B, Uzman O, Nver E, Akkaya E. CT- guided transthoracic fine needle aspiration of pulmonary lesions: accuracy and complications in $294 \mathrm{pa}-$ tients. Med Sci Monit. 2002 Jul;8(7):CR493-7.
5 Yung RC. Tissue diagnosis of suspected lung cancer: selecting between bronchoscopy, transthoracic needle aspiration, and resectional biopsy. Respir Care Clin N Am. 2003 Mar;9(1):51-76.

6 Vilmann P, Clementsen PF, Colella S, Siemsen $M$, De Leyn P, Dumonceau JM, et al. Combined endobronchial and oesophageal endosonography for the diagnosis and staging of lung cancer. European Society of Gastrointestinal Endoscopy (ESGE) Guideline, in cooperation with the European Respiratory Society (ERS) and the European Society of Thoracic Surgeons (ESTS). Eur Respir J. 2015 Jul;46(1):40-60.

7 De Leyn P, Dooms C, Kuzdzal J, Lardinois D, Passlick B, Rami-Porta R, et al. Revised ESTS guidelines for preoperative mediastinal lymph node staging for non-small-cell lung cancer. Eur J Cardiothorac Surg. 2014 May; 45(5):787-98.
8 Silvestri GA, Gonzalez AV, Jantz MA, Margolis ML, Gould MK, Tanoue LT, et al. Methods for staging non-small cell lung cancer: Diagnosis and management of lung cancer, 3rd ed: American College of Chest Physicians evidence-based clinical practice guidelines. Chest. 2013 May;143(5 Suppl):e211S-50S.

9 Nakajima T, Yasufuku K, Fujiwara T, Chiyo M, Sekine Y, Shibuya K, et al. Endobronchial ultrasound-guided transbronchial needle aspiration for the diagnosis of intrapulmonary lesions. J Thorac Oncol. 2008 Sep;3(9):985-8.

10 Colella S, Vilmann P, Konge L, Clementsen PF. Endoscopic ultrasound in the diagnosis and staging of lung cancer. Endosc Ultrasound. 2014 Oct;3(4):205-12.

11 McInnes MD, Moher D, Thombs BD, McGrath TA, Bossuyt PM, Clifford T, et al.; the PRISMA-DTA Group. Preferred Reporting Items for a Systematic Review and Meta-analysis of Diagnostic Test Accuracy Studies: the PRISMA-DTA Statement. JAMA. 2018 Jan; 319(4):388-96.
EBUS-TBNA and the Diagnosis of Centrally Located Lung Tumors 
12 Whiting PF, Rutjes AW, Westwood ME, Mallett S, Deeks JJ, Reitsma JB, et al.; QUADAS-2 Group. QUADAS-2: a revised tool for the quality assessment of diagnostic accuracy studies. Ann Intern Med. 2011 Oct;155(8): 529-36.

13 DerSimonian R, Laird N. Meta-analysis in clinical trials. Control Clin Trials. 1986 Sep; 7(3):177-88.

14 Tournoy KG, Rintoul RC, van Meerbeeck JP, Carroll NR, Praet M, Buttery RC, et al. EBUSTBNA for the diagnosis of central parenchymal lung lesions not visible at routine bronchoscopy. Lung Cancer. 2009 Jan;63(1):45-9.

15 Eckardt J, Olsen KE, Licht PB. Endobronchial ultrasound-guided transbronchial needle aspiration of undiagnosed chest tumors. World J Surg. 2010 Aug;34(8):1823-7.

16 Khan SL, Haris M, Diver S, Miller B, Munavvar M. Can endobronchial ultrasound (EBUS) guided transbronchial needle aspiration (TBNA) be used as a first line investigation in the diagnosis of central lung parenchymal lesion? Thorax 2012;67(Suppl 2):A94

17 Bhatti HA, Bajwa A, Bhatti JA, Cury J, Shujaat A, Jones L, et al. Diagnostic yield of EBUSTBNA for the evaluation of centrally located peribronchial pulmonary lesions. J Bronchology Interv Pulmonol. 2013 Apr;20(2):107-12.

18 Verma A, Jeon K, Koh WJ, Suh GY, Chung $\mathrm{MP}, \mathrm{Kim} \mathrm{H}$, et al. Endobronchial ultrasoundguided transbronchial needle aspiration for the diagnosis of central lung parenchymal lesions. Yonsei Med J. 2013 May;54(3):672-8.

19 Yang HZ, Teng JJ, Zhong RB, Zhang J, Sun JY, Han BH. [Endobronchial ultrasound-guided transbronchial needle aspiration in the diagnosis of intrapulmonary lesions]. Zhonghua Jie He He Hu Xi Za Zhi. 2013 Jan;36(1):17-21.

20 Zhao H, Xie Z, Zhou ZL, Sui XZ, Wang J. Diagnostic value of endobronchial ultrasoundguided transbronchial needle aspiration in intrapulmonary lesions. Chin Med J (Engl). 2013 Nov; 126(22):4312-5.

21 Evison M, Crosbie P, Martin J, Barber R, Booton R. Endobronchial ultrasound in the diagnosis of malignant intra-parenchymal lung lesions - a tertiary centre experience over 2.5 years. Lung Cancer. 2013;79:S23-4.
22 Argento AC, Puchalski J. Convex probe EBUS for centrally located parenchymal lesions without a bronchus sign. Respir Med. 2016 Jul;116:55-8.

23 Chen C, Mu CY, Su MQ, Mao JY, Zhu YH, Huang JA. Endobronchial Ultrasound-guided Transbronchial Needle Aspiration Increases the Yield of Transbronchial Lung Biopsy for the Evaluation of Peribronchial Lesions. Chin Med J (Engl). 2017 Jan;130(1): 11-4.

24 Almeida FA, Salam S, Mehta AC, Yuhico L, Sarda Y, Choi H, et al. Sampling utility of the convex probe endobronchial ultrasound visible intrapulmonary lesion. J Bronchology Interv Pulmonol. 2018 Oct;25(4):290-9.

25 Guarize J, Casiraghi M, Donghi S, Diotti C, Vanoni N, Romano R, et al. Endobronchial Ultrasound Transbronchial Needle Aspiration in Thoracic Diseases: Much More than Mediastinal Staging. Can Respir J. 2018 Mar; 2018:4269798.

26 Chaiyakul S. Endobronchial ultrasoundguided transbronchial needle aspiration for the diagnosis of central intrapulmonary lesions not visible by conventional bronchoscopy. Med Assoc Thai 2018;101(7):939-47

27 Ettinger DS, Akerley W, Borghaei H, Chang AC, Cheney RT, Chirieac LR, et al.; National comprehensive cancer network. Non-small cell lung cancer, version 2.2013. J Natl Compr Canc Netw. 2013 Jun;11(6):645-53.

28 Konge L, Colella S, Vilmann P, Clementsen $\mathrm{PF}$. How to learn and to perform endoscopic ultrasound and endobronchial ultrasound for lung cancer staging: A structured guide and review. Endosc Ultrasound. 2015 Jan-Mar; 4(1):4-9.

29 Vaidya PJ, Munavvar M, Leuppi JD, Mehta AC, Chhajed PN. Endobronchial ultrasoundguided transbronchial needle aspiration: safe as it sounds. Respirology. 2017 Aug;22(6): 1093-101.

30 Rintoul RC, Glover MJ, Jackson C, Hughes V, Tournoy KG, Dooms C, et al. Cost effectiveness of endosonography versus surgical staging in potentially resectable lung cancer: a health economics analysis of the ASTER trial from a European perspective. Thorax. 2014 Jul;69(7):679-81.
31 Farr A, Clementsen P, Herth F, Konge L, Rohde G, Dowsland S, et al. Endobronchial ultrasound: launch of an ERS structured training programme. Breathe (Sheff). 2016 Sep; $12(3): 217-20$.

32 Micames CG, McCrory DC, Pavey DA, Jowell PS, Gress FG. Endoscopic ultrasound-guided fine-needle aspiration for non-small cell lung cancer staging: A systematic review and metaanalysis. Chest. $2007 \mathrm{Feb}$;131(2):539-48.

33 Shin SH, Jeong DY, Lee KS, Cho JH, Choi YS, Lee $\mathrm{K}$, et al. Which definition of a central tumour is more predictive of occult mediastinal metastasis in nonsmall cell lung cancer patients with radiological N0 disease? Eur Respir J. 2019 Mar;53(3):1801508.

34 Zaric B, Eberhardt R, Herth F, Stojsic V, Carapic V, Popovic ZP, et al. Linear and radial endobronchial ultrasound in diagnosis and staging of lung cancer. Expert Rev Med Devices. 2013 Sep;10(5):685-95.

35 Steinfort DP, Khor YH, Manser RL, Irving LB. Radial probe endobronchial ultrasound for the diagnosis of peripheral lung cancer: systematic review and meta-analysis. Eur Respir J. 2011 Apr;37(4):902-10.

36 Ernst A, Anantham D, Eberhardt R, Krasnik $M$, Herth FJ. Diagnosis of mediastinal adenopathy-real-time endobronchial ultrasound guided needle aspiration versus mediastinoscopy. J Thorac Oncol. 2008 Jun;3(6):577-82.

37 Korevaar DA, Colella S, Spijker R, Bossuyt PM, Konge L, Clementsen PF, et al. Esophageal Endosonography for the Diagnosis of Intrapulmonary Tumors: A Systematic Review and Meta-Analysis. Respiration. 2017;93(2): $126-37$.

38 Vilmann P, Clementsen PF. Combined EUS and EBUS are complementary methods in lung cancer staging: do not forget the esophagus. Endosc Int Open. 2015 Aug;3(4):E300-1.

39 Bugalho A, Ferreira D, Eberhardt R, Dias SS, Videira PA, Herth FJ, et al. Diagnostic value of endobronchial and endoscopic ultrasoundguided fine needle aspiration for accessible lung cancer lesions after non-diagnostic conventional techniques: a prospective study. BMC Cancer. 2013 Mar;13(1):130. 